\title{
Caracterização biométrica e superação de dormência de sementes de Pithecellobium diversifolium Benth.
}

\section{Biometric characterization and dormancy overcoming of seeds of Pithecellobium diversifolium Benth.}

\author{
Denisson Lima do Nascimento (D1), Jailson de Oliveira (D1, Fábio José Marques², Cosmo Rufino de Lima³,

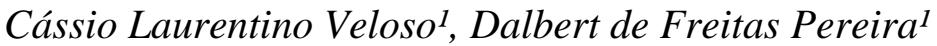

${ }^{1}$ Graduando em Engenharia Agronômica no Instituto Federal de Educação, Ciência e Tecnologia de Alagoas, Campus Piranhas, Piranhas, denisso2011@ @hotmail.com; jailson.2110@gmail.com; cassioveloso2008@ hotmail.com; dalbert.freitas@ gmail.com. 2Professor do Instituto Federal de Educação, Ciência e Tecnologia de Alagoas, Campus Piranhas, Piranhas, fabio.marques@ifal.edu.br. ${ }^{3}$ Professor do Instituto Federal de Pernambuco, Campus Afogados da Ingazeira, Afogados, cosmo.rufino@afogados.ifpe.edu.br.

\section{N O T A}

Recebido: 22/04/2020

Aprovado: 09/01/2021

Palavras-chave:

Carcarazeiro

Semiárido

Caatinga

Espécie florestal

Vigor

\section{R E S U M O}

Pithecellobium diversifolium Benth. é um arbusto nativo com vasta ocorrência nos estados do Nordeste brasileiro. O crescente interesse na propagação e no cultivo de espécies florestais nativas demanda informações básicas sobre as características biométrica e germinativas das suas sementes para sua propagação. Com isso, o objetivo do trabalho foi caracterizar as sementes e avaliar o processo germinativo de $P$. diversifolium submetidos a métodos de superação de dormência. $\mathrm{O}$ experimento foi conduzido no Laboratório de Produção Vegetal do Instituto Federal de Alagoas, localizado no município de Piranhas-AL, onde foram coletadas as sementes. Foi realizada a caracterização física das sementes, determinando-se o teor de água, o peso de 1.000 sementes, e o comprimento, largura e espessura das sementes. Foram utilizados cinco tratamentos para superação de dormência: (T1) intactas; (T2) escarificação mecânica com lixa d'água $n^{\circ}$ 80; (T3) fragmentação do tegumento; (T4) imersão em água a $90{ }^{\circ} \mathrm{C}$ por $1 \mathrm{~min}$; e (T5) imersão em água por 24 horas. As avaliações do teste de germinação foram feitas diariamente, durante 26 dias. Os parâmetros avaliados foram primeira contagem de germinação; porcentagem de germinação; índice de velocidade de germinação; comprimento da parte aérea e da raiz principal; massa seca da parte aérea e raiz. O delineamento experimental utilizado foi o Inteiramente Casualizado com quatro repetições de 50 sementes por tratamento. Dessa forma, as sementes possuem variabilidade em suas características biométricas avaliadas, e a escarificação mecânica com lixa d'água é o método recomendado para superar a dormência das sementes de $P$. diversifolium.

\section{A B S T R A C T}

Key words:

Carcarazeiro

Semiarid

Caatinga

Forest species

Force
Pithecellobium diversifolium Benth. it is a native shrub with wide occurrence in the states of Northeast Brazil. The growing interest in the propagation and cultivation of native forest species demands basic information about the biometric and germinative characteristics of their seeds for their propagation. With that, the objective of the work was to characterize the seeds and evaluate the germinative process of $P$. diversifolium submitted to dormancy overcoming methods. The experiment was conducted at the Vegetable Production Laboratory of the Federal Institute of Alagoas, located in the municipality of Piranhas-AL, where the seeds were collected. The physical characterization of the seeds was carried out, determining the water content, the weight of 1.000 seeds, and the length, width and thickness of the seeds. Five treatments were used to overcome dormancy: (T1) intact; (T2) mechanical scarification with sandpaper $\mathrm{n}^{\circ}$ 80; (T3) fragmentation of the integument; (T4) immersion in water at $90{ }^{\circ} \mathrm{C}$ for $1 \mathrm{~min}$; and (T5) immersion in water for 24 hours. The germination test evaluations were performed daily, for 26 days. The parameters evaluated were first germination count; germination percentage; germination speed index; shoot and main root length; dry mass of shoot and root. The completely randomized design was used with four replications of 50 seeds per

\author{
Revista Verde \\ ISSN 1981-8203 \\ Pombal, Paraíba, Brasil
}

v. 16, n.2, abr.-jun, p.103-110, 2021

doi: $10.18378 /$ rvads.v16i2.7884 
treatment. In this way, the seeds have variability in their evaluated biometric characteristics, and mechanical scarification with sandpaper is the recommended method to overcome the dormancy of $P$. diversifolium seeds.

\section{INTRODUÇÃO}

A Caatinga, vegetação predominante na região Semiárida, é um bioma exclusivamente brasileiro (VASCONCELOS et al., 2017). Com características únicas e sendo fornecedora de recursos energéticos, alimentícios, madeireiros, forrageiros e medicinais para a população local (GOMES et al., 2018), ela é composta principalmente por espécies cactáceas e arbustivas de grande importância regional. Sua vegetação é caracterizada por apresentar sobretudo matas secas, o que se torna importante a adaptação dessas espécies a esses fatores abióticos, sendo preferencialmente adotados diversos mecanismos de sobrevivência para sua melhor adequação.

Pithecellobium diversifolium Benth., pertence à família Fabaceae, é um arbusto com folhas do tipo composta e sementes em vagem de coloração marrom, com vasta ocorrência nos estados do Nordeste brasileiro, sendo popularmente conhecida por carcarazeiro (LOVO, 2019). Segundo Lovo (2019), a espécie é utilizada para fins medicinais através das suas entrecascas, raízes, folhas, para realização de paisagismo e de reflorestamento de áreas degradadas. Além disso, diante de várias espécies que apresentam importância na Caatinga, estudos com a $P$. diversifolium são muitos escassos na literatura, sobretudo em relação a suas formas de propagação, etapa fundamental para garantir a perpetuação de uma espécie.

Para caracterizar e obter maiores conhecimentos das espécies florestais nativas, é fundamental a realização de pesquisas nos aspectos morfológicos e fisiológicos. Neste contexto, estudos relacionados à biometria e a germinação de sementes são importantes, pois fornecem informações necessárias para a conservação e manejo adequado das espécies (BONAMIGO et al., 2019). Segundo Feliz et al. (2020), a análise biométrica de sementes pode fornecer resultados importantes para a conservação e exploração de espécies florestais nativas, contribuindo assim para o reflorestamento e com programas de melhoramento genético. Além disso, a biometria é considerada como fundamento para o estudo de dispersão e estabelecimento de plântulas, e para diferenciar espécies pertencentes a diferentes grupos ecológicos em florestas tropicais (BASKIN; BASKIN, 2014).

Visando superar a dormência de plantas nativas, diferentes metodologias foram desenvolvidas, objetivando acelerar um processo que teoricamente ocorreria naturalmente em condições favoráveis (PORTO et al., 2019). Segundo Carvalho et al. (2019), a escarificação química, mecânica e a imersão em água quente destacam-se entre os métodos utilizados com sucesso para a superação da dormência de espécies florestais. Vale salientar que a germinação das sementes envolve uma sequência de eventos fisiológicos que são influenciados por diversos fatores, internos e externos (GONÇALVES et al., 2020).

$\mathrm{O}$ estudo de metodologias referente aos aspectos biométricos e de germinação de sementes de $P$. diversifolium, é de grande importância, uma vez que tais resultados contribuirão para o conhecimento da espécie levando em consideração a possibilidade em sua eficácia de seus propágulos, tendo em vista que pesquisas como essa podem indicar a espécie para projetos de enriquecimento e restauração, sendo muito importante para os viveiristas. Sendo assim, a classificação das sementes por tamanho ou por massa pode ser uma estratégia para uniformizar a emergência das plântulas e selecionar sementes com maior vigor, pois podem otimizar o uso desta espécie (ARAÚJO et al., 2014). Dessa forma, o objetivo deste trabalho foi caracterizar as sementes do ponto de vista físico e indicar o melhor método para superação de dormência de sementes de $P$. diversifolium.

\section{MATERIAL E MÉTODOS}

O experimento foi conduzido no Laboratório de Produção Vegetal do Instituto Federal de Educação, Ciência e Tecnologia de Alagoas (IFAL), localizado no município de Piranhas, no Estado de Alagoas (latitude de 9'37'22,42"S, longitude de $37^{\circ} 46^{\prime} 1,51^{\prime}$ 'W e altitude de $178 \mathrm{~m}$ ). O clima da região de acordo com a classificação de Köppen, é BSh, tropical, semiárido, com estação chuvosa entre abril e julho (SANTOS, et al., 2017).

As sementes de $P$. diversifolium foram coletadas em 2 árvores localizada na região de Caatinga no município de Piranhas, nas coordenadas geográficas Latitude de $9^{\circ} 36^{\prime} 16,90$ 'S e Longitude de $37^{\circ} 46^{\prime} 07,48^{\prime \prime} \mathrm{W}$, sertão do Estado de Alagoas, sendo o trabalho realizado entre os meses de agosto e setembro de 2019. Imediatamente após a coleta, foi realizada uma triagem para limpeza e separação das sementes malformadas e ou predadas.

As determinações biométricas foram feitas com auxílio de um paquímetro digital da marca $\mathrm{Zaas}^{\Theta}$, com precisão de 0,01 $\mathrm{mm}$, sendo utilizada uma amostra ao acaso de 100 sementes. Os dados biométricos das sementes foram obtidos medindo-se o comprimento, largura e espessura, e para avaliações de peso, foi utilizada balança analítica com sensibilidade de 0,0001 g. O teor de água foi obtido pelo método de estufa a $105 \pm 3{ }^{\circ} \mathrm{C}$ por 24 h, descrito nas Regras para Análise de Sementes (BRASIL, 2009).

Para a superação da dormência, as sementes foram submetidas a cinco diferentes tratamentos: (T1) Intactas; (T2) Escarificação mecânica com lixa d'água $\mathrm{n}^{\circ} 80$ do lado oposto à micrópila; (T3) Fragmentação do tegumento, sendo comprimido no sentido da base para o ápice; (T4) Imersão em água a $90{ }^{\circ} \mathrm{C}$ por 1 min; e (T5) Imersão em água por 24 horas.

No tratamento 2, a escarificação mecânica foi realizada do lado oposto à micrópila até o rompimento da testa e exposição inicial do cotilédone. A fragmentação foi obtida comprimindose individualmente os tegumentos, no sentido da base para o ápice. As sementes com imersão em água a $90{ }^{\circ} \mathrm{C}$ foram imersas em Béquers de $50 \mathrm{~mL}$, durante 1 minuto. $\mathrm{O}$ delineamento experimental utilizado foi $\mathrm{o}$ inteiramente casualizado, com cinco tratamentos em quatro repetições, com 50 sementes cada, totalizando 1000 sementes.

Após a aplicação dos tratamentos, as sementes foram colocadas para germinar. Para tanto, quatro repetições de 50 sementes foram distribuídas sobre duas folhas de papel tipo germitest ${ }^{\circledR}$, umedecidas com quantidade de água equivalente a 
2,5 vezes o peso do papel, sendo cobertas com uma folha, segundo Brasil (2009). Foram confeccionados rolos que foram mantidos em câmara de germinação tipo Biochemical Oxigen Demand (B.O.D.) a temperatura constante de $30{ }^{\circ} \mathrm{C}$, sob fotoperíodo de 12 horas. As avaliações do teste de germinação foram feitas diariamente, durante 26 dias (BRASIL, 2009).

A partir de contagens diárias foram determinadas as seguintes variáveis: primeira contagem de germinação (PCG), com valores registrados aos três dias após a semeadura; índices de velocidade de germinação (IVG); comprimento da parte aérea (CPA); comprimento da raiz principal (CR); massa seca da parte aérea (MSPA) e massa seca da raiz (MSR). O IVE foi determinado de acordo com a equação proposta por Maguire (1962).

A determinação do CPA foi realizada com o auxílio de uma régua graduada, medindo-se a distância entre a base do colo e o ápice da plântula em centímetros. Para o CR, realizouse com base nas mensurações obtidas a partir da região de transição entre a raiz e o caule até a extremidade da raiz principal, sendo os resultados expressos em centímetros por plântula. Em relação à MSPA e MSR foram obtidos após secagem em estufa de circulação forçada de ar, a $65{ }^{\circ} \mathrm{C}$ por 48 horas, até atingir massa constante, sendo em seguida, pesada em balança analítica com precisão de $0,0001 \mathrm{~g}$ e os resultados expressos em gramas por plântula (NAKAGAWA, 1999).

Os dados foram submetidos à análise de variância utilizando-se o teste $\mathrm{F}$, e as médias foram comparadas pelo teste de Tukey a 5\% de probabilidade, utilizando o software Sisvar ${ }^{\circledR}$ (FERREIRA, 2014). Os dados de PCG foram transformados por $\sqrt{x}$ para atender as suposições da análise de variância. Para os dados da biometria das sementes utilizou-se estatística descritiva, obtendo-se as respectivas médias, moda, desvio padrão e coeficiente de variação. Além disso, foram analisados por meio de distribuição de frequência e plotados em histogramas.

\section{RESULTADOS E DISCUSSÃO}

As sementes de carcarazeiro apresentaram em média 6,7 $\mathrm{mm}$ de comprimento, $6,9 \mathrm{~mm}$ de largura e $4,3 \mathrm{~mm}$ de espessura. A variável comprimento apresentou $6,1 \mathrm{~mm}$ e $7,2 \mathrm{~mm}$ em mínimo e máximo, respectivamente. Medidas similares são observadas na largura, no qual, o mínimo apresentou $6,5 \mathrm{~mm}$ e o máximo, 7,4 mm. Já a espessura, apresentou mínimo e máximo $3,7 \mathrm{~mm}$ e 5,0 $\mathrm{mm}$, respectivamente (Tabela 1). Segundo Rodrigues et al. (2006), a grande variação observada no tamanho das sementes é de ocorrência comum em frutos polispérmicos, por haver competição, interferindo no tamanho final, sendo que, na maioria das vezes, sementes das extremidades apresentam tamanho reduzido.

De acordo com Pinheiro et al. (2017), o tamanho da semente é importante, pois apresenta característica que pode influenciar na germinação da espécie, no qual, a variação indica maior ou menor concentração de reserva nutritiva na mesma. Pela mesma razão que o tamanho das sementes, em muitas espécies, é indicativo de sua qualidade fisiológica, pois dentro do mesmo lote as sementes pequenas apresentam menores valores de germinação e vigor que as de tamanhos médio e grande, estando associada ao ambiente ao qual a planta mãe está inserida (SILVA et al., 2017; SANTOS et al., 2019).
Tabela 1. Comprimento, largura, espessura de sementes de Pithecellobium diversifolium Benth., Piranhas, Alagoas

\begin{tabular}{lccc}
\hline Parâmetros & $\begin{array}{c}\text { Comprimento } \\
(\mathrm{mm})\end{array}$ & $\begin{array}{c}\text { Largura } \\
(\mathrm{mm})\end{array}$ & $\begin{array}{c}\text { Espessura } \\
(\mathrm{mm})\end{array}$ \\
\hline Média & 6,7 & 6,9 & 4,3 \\
Moda & 6,8 & 6,8 & 4,0 \\
Mediana & 6,8 & 6,8 & 4,1 \\
Mínimo & 6,1 & 6,5 & 3,7 \\
Máximo & 7,2 & 7,4 & 5,0 \\
Desvio Padrão & 0,2 & 0,2 & 0,4 \\
\hline CV $(\%)$ & 3,8 & 3,7 & 10,0 \\
\hline
\end{tabular}

O coeficiente de variação das três variáveis apresentaram $3,8 \%$ para o comprimento, $3,7 \%$ para a largura e $10,0 \%$ para a espessura, no qual possuíram valores baixos indicando que a amostragem e a avaliação biométrica das sementes foram bem conduzidas. Segundo Abreu et al. (2017) esta variação dos valores atua como indicativo de heterogeneidade nas dimensões das sementes.

Pelos histogramas de frequência (Figura 1), observou-se que houve um comportamento assimétrico, indicando que as variáveis comprimento, largura e espessura, apresentaram valores distintos. Observou-se ainda que as maiores frequências no comprimento (Figura 1A), encontram-se nos intervalos de 6,5 a $6,64 \mathrm{~mm}$ e 6,78 a $6,92 \mathrm{~mm}(90 \%)$, largura (Figura 1B) entre 6,78 a 6,79 mm (90\%) e espessura (Figura 1C) entre 3,76 a 4,07 mm (78\%). Segundo Valadares, Paula e Moro (2009), fazendo a caracterização de sementes de Poecilanthe parviflora Benth. encontraram baixa variação no comprimento, largura e espessura destas sementes, sendo este fato podendo ser explicado pela decorrência das sementes terem sido colhidas em matrizes muito próximas umas das outras, havendo assim baixa variabilidade genética.

Para a largura das sementes, houve uma assimetria acentuada a esquerda do gráfico. Silva et al. (2013), ao estudarem os aspectos biométricos de frutos e sementes de Melanoxylon brauna, relataram que as sementes apresentaram largura com assimetria à esquerda, comportamento este observado no presente trabalho em estudo. Estima-se que as variações decorrentes das características de sementes sejam influenciadas pela disponibilidade hídrica durante o desenvolvimento da planta (MARCOS FILHO, 2015).

O peso de mil sementes de $P$. diversifolium foi de $11,18 \mathrm{~g}$. De acordo com Menezes et al. (2018), o tamanho e o peso das sementes para algumas espécies podem ser considerados um indicativo de sua qualidade fisiológica, sendo que em um mesmo lote, sementes mais leves, normalmente, apresentam menor desempenho do que as mais pesadas.

Quanto ao teor de água das sementes de $P$. diversifolium, resultou em 11,5\%. Segundo Hoppe et al. (2004), espécies que geralmente possuem sementes ortodoxas mantêm sua viabilidade com teores de água entre 8 e 12\%, ficando pouco susceptíveis à deterioração por agentes bióticos ou pela queima de suas reservas. Sarmento et al. (2015) relata que o teor de água das sementes influencia diretamente em vários aspectos de sua qualidade fisiológica, por isso a sua determinação é fundamental em testes oficiais de qualidade de lotes de sementes. 
Figura 1. Frequência relativa (Fr) para comprimento (A), largura (B) e espessura (C) de sementes de Pithecellobium diversifolium Benth., Piranhas, Alagoas
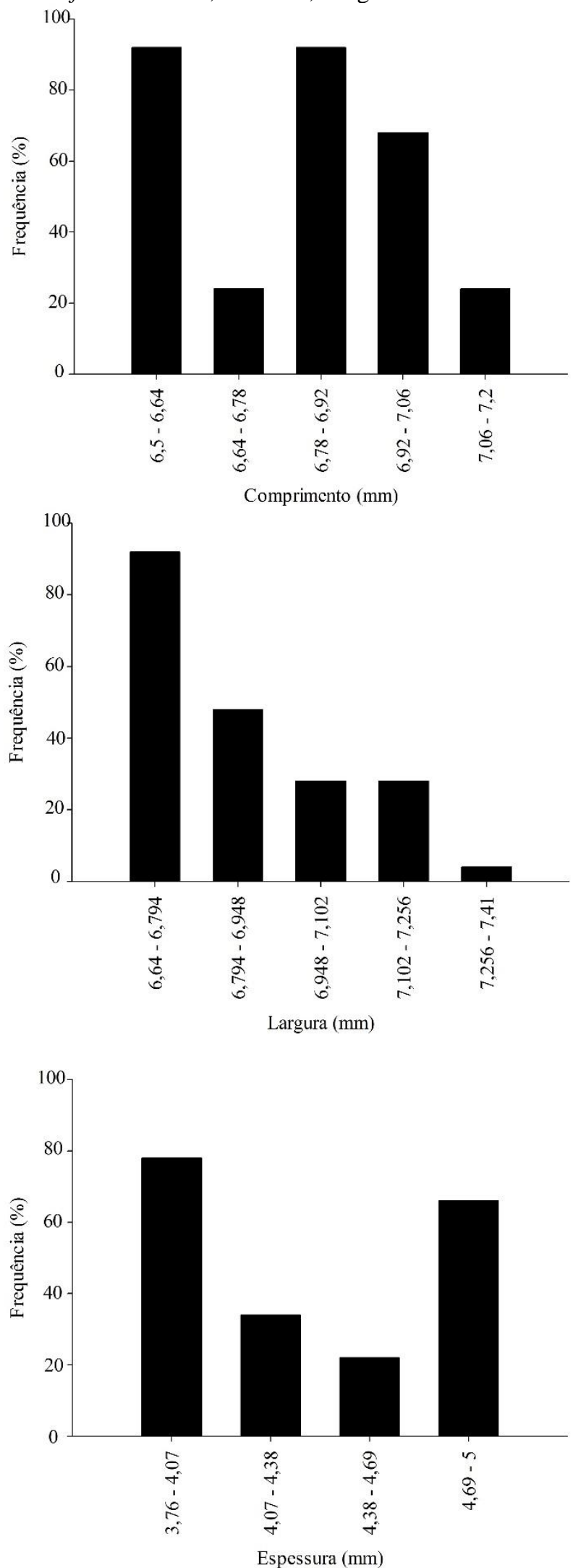

Para todas as variáveis mensuradas houve diferença significativa entre os tratamentos avaliados. Na primeira contagem de germinação (PCG \%) das sementes, os tratamentos fragmentação do tegumento (T3) e escarificação mecânica com lixa d'água $\mathrm{n}^{\circ} 80$ (T2) apresentaram as maiores médias com 34 e $28 \%$ respectivamente, não diferindo estatisticamente do método de imersão em água por 24 horas (T5) com média de $21 \%$. Este, porém, foi semelhante ao tratamento de forma intactas (T1), e sendo a imersão em água a $90{ }^{\circ} \mathrm{C}$ por 1 min (T4) com a menor média (Figura 2B). Gama et al. (2011) pesquisando a superação de dormência em sementes de Centrosema plumieri BENTH., perceberam que a escarificação com lixa d'água apresentaram os maiores resultados, pois, além de eficiente, dispensam menor tempo na superação da domerência. De acordo com Bhering (2000), o teste de primeira contagem de germinação pode ser utilizado para se obter informações preliminares sobre o vigor das sementes.

$\mathrm{Na}$ avaliação da percentagem de germinação $(\% \mathrm{G})$ podese observar que o uso da escarificação mecânica com lixa d'água $n^{\circ} 80$ (T2), proporcionou valores médios superiores aos demais tratamentos, com $97 \%$ das sementes germinadas. O

B tratamento com as sementes intactas (T1) e a imersão em água por 24 horas (T5) apresentaram resultados semelhantes estatisticamente. A menor média foi expressada pelo tratamento imersão em água a $90{ }^{\circ} \mathrm{C}$ por $1 \mathrm{~min}$ (T4) (Figura 2A). Esses dados comprovam que as sementes de $P$. diversifolium realmente apresentam dormência, provavelmente devido ao seu tegumento, um sistema de impedimento a entrada de água. Para Cardoso (2012), do ponto de vista fisiológico, a entrada de água na semente, facilitada pela escarificação, proporciona a diminuição do ácido abscísico (ABA) (que inibia os processos de germinação) e a produção de ácidos graxos (AG) necessários para o desencadeamento do processo germinativo, desse modo, facilitando o processo pré-germinativo da semente.

Em relação ao índice de velocidade de germinação (IVG), constatou-se resultado estatisticamente superior para o tratamento escarificação mecânica com lixa d'água no 80 (T2), obtendo um índice médio de 10,39. Sendo logo em seguida o tratamento fragmentação do tegumento (T3) e a imersão em água por 24 horas (T5), que não apresentaram diferenças,

C posteriormente, as sementes intactas (T1) e com menor média a imersão em água a $90{ }^{\circ} \mathrm{C}$ por 1 min (T4) (Figura 2C). Assim, técnicas de superação de dormência que proporcionem elevar o índice de velocidade de germinação são importantes para garantir produção de mudas florestais de maneira mais uniforme. Nesse sentido, a eficiência desse tratamento favoreceu a expressão do seu máximo potencial fisiológico. Corroborando com esse estudo, Pacheco e Matos (2009) trabalhando com superação de dormência com sementes de Apeiba tibourbou Aubl, também encontram maiores porcentagens de germinação para os tratamentos que obtiveram maior valor no IVG. 
Figura 2. Parâmetros em plântulas em diferentes métodos de quebra de dormência na germinação de sementes de Pithecellobium diversifolium Benth. (A) Germinação (CV: 14,07\%); (B) primeira contagem de germinação (CV: 28,09\%); (C) índice de velocidade de germinação (CV: 11,72\%); (D) comprimento da parte aérea (CV: 19,50\%); (E) comprimento da raiz (CV: 22,04\%); (F), massa seca da parte aérea (CV: 17,78\%) e (G) massa seca da raiz (CV: 22,51\%). T1 - Intactas. T2 - Escarificação mecânica com lixa d'água $\mathrm{n}^{\circ} 80$ do lado oposto à micrópila. T3 - Fragmentação do tegumento, sendo comprimido no sentido da base para o ápice. T4 - Imersão em água a $90{ }^{\circ} \mathrm{C}$ por 1 min. T5 - Imersão em água por 24 horas.

$$
\text { A }
$$

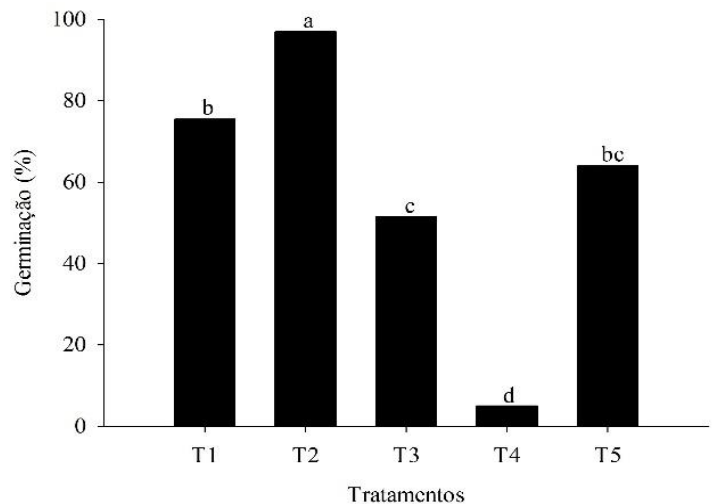

C
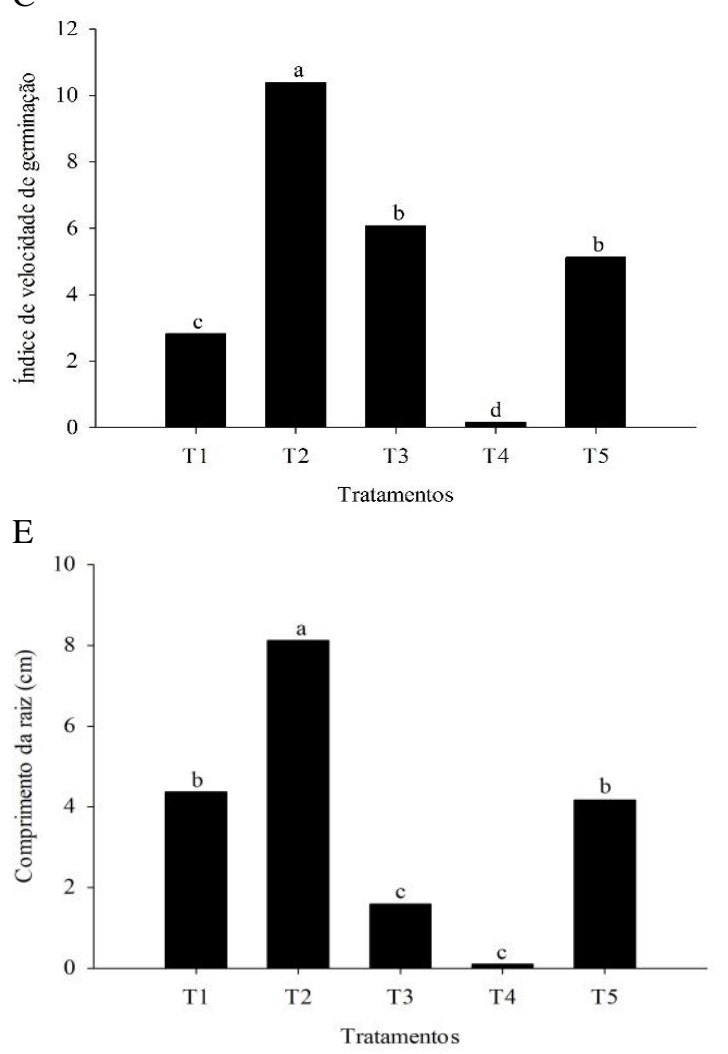

E

G

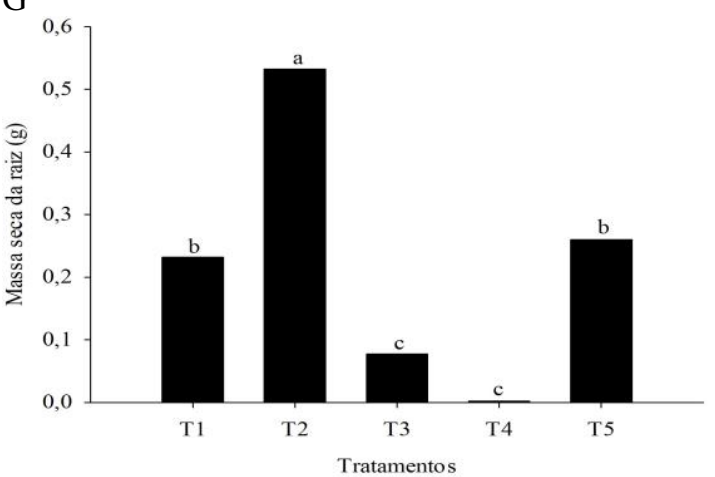

B

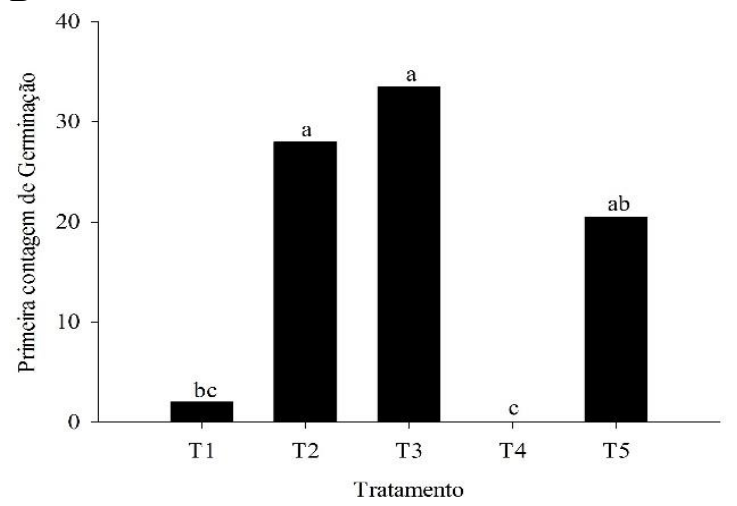

D

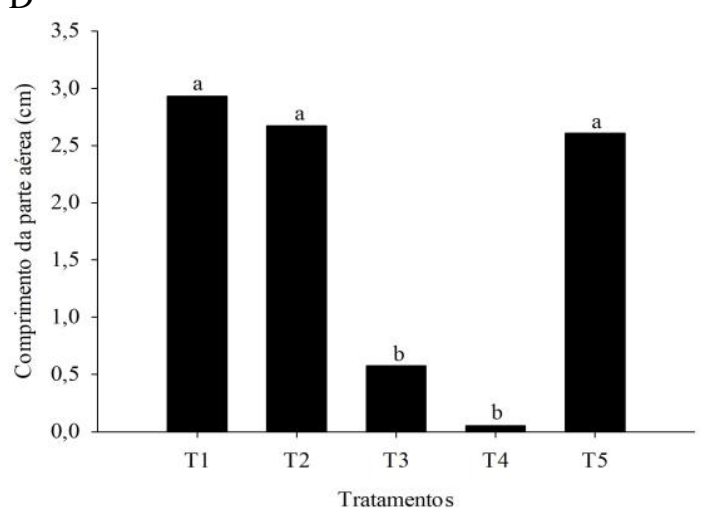

F

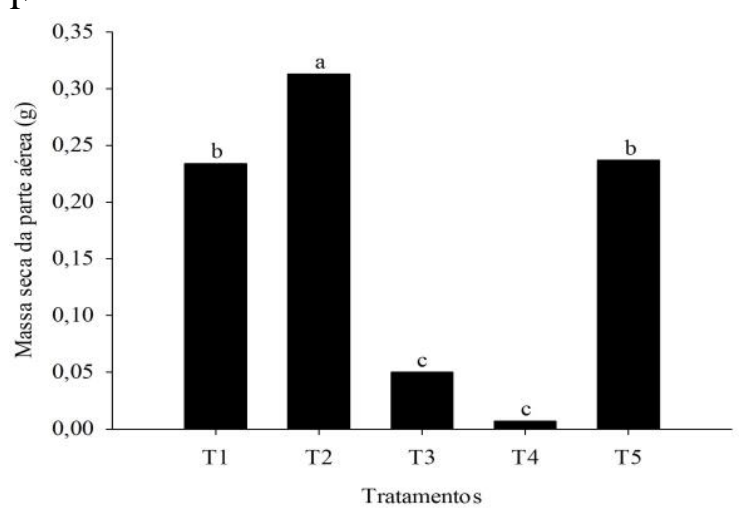


Para a variável comprimento da parte aérea (CPA) houve diferença significativa entre os tratamentos, sendo os métodos sementes sem tratamento (T1), escarificação mecânica com lixa d'água $\mathrm{n}^{\circ} 80$ (T2) e imersão em água por 24 horas (T5) os que apresentaram médias superiores aos demais, com médias de 2,932, 2,674 e 2,609 cm, respectivamente, mas não diferindo estatisticamente entre si. Os tratamentos que proporcionaram os menores comprimentos foram a fragmentação do tegumento (T3) e a imersão em água a $90{ }^{\circ} \mathrm{C}$ por 1 min (T4) (Figura 2D). Segundo Coelho e Ribeiro (2018), isso é um fator que depende de variáveis como o IVG, no qual a germinação mais rápida pode antecipar o momento de transplante para o local definitivo. Trabalhando com sementes de Caesalpinia pyramidalis Tul., Alves et al. (2007) obtiveram resultados semelhantes quando as mesmas foram manualmente escarificadas com lixa número 80.

Quanto ao comprimento da raiz (CR) das plântulas, os maiores valores foram obtidos com o método escarificação mecânica com lixa d'água ${ }^{\circ} 80$ (T2) com valor médio de 8,118 $\mathrm{cm}$ do comprimento do sistema radicular (Figura 2E). Isso pode ser explicado pelo fato de que a escarificação é um método considerado eficaz para superação de dormência de sementes causada pela impermeabilidade do tegumento, de muitas espécies, pois faz com que rompa a barreira e facilite as trocas gasosas e a entrada de água na semente, desencadeando o processo germinativo, como comprovado em estudos realizados por Rosa et al. (2012) em Mimosa scabrella, Oliveira et al. (2012a) em Samanea tubulosa e Oliveira et al. (2012b) em Parkia gigantocarpa.

Quando o vigor das plântulas foi avaliado através da massa seca da parte aérea (MSPA) e da raíz (MSR), foi observado o mesmo comportamento, em que o maior peso foi encontrado no método escarificação mecânica com lixa d'água $\mathrm{n}^{\circ} 80$ (T2) atingindo uma média de 0,313 g e 0,532 g, respectivamente, diferindo estatisticamente dos demais tratamentos avaliados (Figura 2F e 2G). Gama et al. (2011) avaliando a superação de dormência, encontraram maiores valores de massa de matéria seca da parte aérea de plântulas da espécie Centrosema plumieri Benth., com o tratamento e escarificação com lixa sem imersão em água. No trabalho de Ferreira et al. (2014), analisando os tratamentos prégerminativos, demonstraram que o tratamento de sementes não escarificadas proporcionou maior acúmulo de massa de matéria seca do sistema radicular das plântulas de Poincianella bracteosa (Tul.) L. P. Queiroz.

\section{CONCLUSÕES}

As sementes de Pithecellobium diversifolium possuem variabilidade em suas características biométricas, sendo associado à variabilidade da espécie.

O tratamento germinativo escarificação mecânica com lixa d'água $\mathrm{n}^{\circ} 80$ é o método recomendado para superar a dormência das sementes de Pithecellobium diversifolium Benth.

\section{REFERÊNCIAS}

ABREU, D. C. A.; PORTO, K. G.; NOGUEIRA, A. C. Métodos de superação da dormência e substratos para germinação de sementes de Tachigali vulgaris L.G. Silva \& H. C. Lima. Floresta Ambient., v. 24, e00071814, jun., 2017. $\underline{10.1590 / 2179-8087.071814 .}$.

ALVES, E. U.; CARDOSO, E. A.; BRUNO, R. L. A.; ALVES, A. U.; ALVES, A. U.; GALINDO, E. A; JUNIOR BRAGA, J. M. Superação da dormência em sementes de caesalpinia pyramidalis Tul. Revista Árvore, Viçosa-MG, v. 31, n. 3, p. 405-415, 2007. 10.1590/S0100-67622007000300006.

ARAÚJO, A. M. S.; TORRES, S. B.; NOGUEIRA, N. W.; FREITAS, R. M. O.; CARVALHO, S. M. C. Caracterização morfométrica e germinação de sementes de Macroptilium martii BENTH. (fabaceae). Revista Caatinga, Mossoró, v. 27, n. 3, p. 124-131, jul./set., 2014. https://search.proquest.com/openview/adcd9c26d43b47476af7f 9d5805d5724/1 ?pqorigsite=gscholar \&cbl=546312.

BASKIN, C. C.; BASKIN, J. M. Seeds: ecology, biogeography, and evolution of dormancy and germination. 2 ed. San Diego: Academic; Elsevier, 2014. 1586 p.

BHERING, M. C. Métodos para avaliação do vigor de sementes de pepino. Revista Brasileira de Sementes, v. 22, n. 2, p. 171$175,2000$.

BONAMIGO, T.; SCALON, S. P. Q.; NUNES, D. P.; PEREIRA, Z. V. Biometria de frutos e germinação de sementes de Tocoyena formosa (Cham. \& Schltdl.) K. Schum. Revista $\begin{array}{llll}\text { Agrarian, } & \text { v.12, } & \text { n.43, } & \text { p.24-32, }\end{array}$ 10.30612/agrarian.v12i43.3455.

BRASIL. Regras para Análise de Sementes. Ministério da Agricultura e Reforma Agrária. SNDA/DNPV/CLAV, 2009. Brasília. 365 p.

CARDOSO, V.J.M. Germinação. In: KERBAUY, G.B. Fisiologia vegetal. 2.ed. Rio de Janeiro: Guanabara Koogan, 2012. p.384-408.

CARVALHO, M. B. F.; ARAÚJO, M. E. R.; MENDONÇA, A. P.; CHÁVEZ, M. S.; GUTIERREZ, K. L. Métodos de superação de dormência da Schizolobium amazonicum Huber ex Ducke. Brazilian Journal of Animal and Environmental Research, Curitiba, v. 2, n. 1, p. 490-500, 2019.

COELHO, T. B.; RIBEIRO, V. A. Superação de dormência em sementes de jatobá. Ipê Agronomic Journal, v. 2, n. 1, p. 14-22, 2018.

FERREIRA, D. F. Sisvar: a guide for its bootstrap procedures in multiple comparisons. Ciência e Agrotecnolgia, Lavras, v. 38, n. 2, p. 109-112, 2014.

FERREIRA, E. G. B S.; FERREIRA, E. G. B. S.; MATOS, V.P.; GONÇALVES, E. P.; FERREIRA, R. L. C e SILVA, R. B. Tratamentos pré-germinativos em sementes de duas espécies 
do gênero Poincianella. Revista Ciência Agronômica, v. 45, n. 3, p. 566-572, 2014.

GAMA, J. S. N.; ALVES, E. U.; BRUNO, R. L. A.; PEREIRA JUNIOR, L. R.; BRAGA JUNIOR, J. B. M.; MONTE, D. M. O. Superação de dormência em sementes de Centrosema plumieri Benth. Revista Brasileira de Sementes, v. 33, n. 4, p. 645-653, 2011. 10.1590/S0101-31222011000400006.

GOMES, D. L.; SILVA, A. P. L.; ARAUJO, K. D.; LIRA, E. S.; SANTOS, E. M. C.; COSTA, J. G. R. Exploração da caatinga em assentamentos rurais do semiárido alagoano caatinga exploration in rural settlements of alagoas semiarido. Revista Ra'e Ga, Curitiba, v. 45, p. 142 - 152, dez., 2018. 10.5380/raega.v45i1.51476.

GONÇALVES, M. P. M.; FELICIANO, A. L. P.; SILVA, A. P.; SILVA, L. B.; SILVA, K. M.; SILVA JÚNIOR, F. S.; GRUGIKI, M. A.; SILVA, M. I. O. Influência de diferentes tipos de solos da Caatinga na germinação de espécies nativas. Brazilian Journal of Development, Curitiba, v. 6, n. 1, p.12161226, 2020. 10.34117/bjdv6n1-085.

HOPPE, J. M.; GENRO, C. J. M.; VARGAS, C. O.; FLORIANO, E. P.; REIS, E. R; FORTES, F. O.; MULLER, I.; FARIAS, J. A.; CALEGARI, L; DACOSTA, L. P. E. Produção de Sementes e Mudas Florestais. $2^{\text {a }}$ ed. Santa Maria: UFSM, 2004. 388 p.

LOVO, A. R. Entre cruzes e flechadas: processos de adoecimento e cura a partir das rezadeiras Pankararu. Revista NUPEM, Campo Mourão, v. 11, n. 24, p. 82-93, 2019. 10.33871/nupem.v11i24.676.

MAGUIRE, J. D. Speed of germination and in selection and evaluation for seedling emergence and vigor. Crop Science, Madison, v. 2, n. 2, p. 176-177, 1962.

MARCOS FILHO, J. Fisiologia de sementes de plantas cultivadas. 2. ed. Londrina: ABRATES, 2015. 659 p.

MENEZES, A. T.; SILVA, J. S.; SANTOS, J. L.; CANGUSSU, A. C. V.; CARDOSO, A. D.; MORAIS, O. M. Características biométricas de sementes de Leucena. Cadernos da Agroecologia. v. 13, n. 1, 2018.

NAKAGAWA, J. Testes de vigor baseados na avaliação das plântulas. In: VIEIRA, R. D.; CARVALHO, N. M. Testes de Vigor em Sementes. Jaboticabal: FUNEP, 1999. p. 49-85.

OLIVEIRA, A. K. M. D.; RIBEIRO, J. W. F.; PEREIRA, K. C. L.; RONDON, E. V.; BECKER, T. J. A.; BARBOSA, L. A. Superação de dormência em sementes de Parkia gigantocarpa (Fabaceae - Mimosidae). Ciência Florestal, v. 22, n. 3, p. 533 540, 2012b. 10.5902/198050986620.

OLIVEIRA, L. M. D.; BRUNO, R. D. L. A.; ALVES, E. U.; SOUSA, D. M. M.; ANDRADE, A. P. D. Tratamentos prégerminativos em sementes de Samanea tubulosa Bentham -
(Leguminoseae-Mimosoideae). Revista Árvore, v. 36, n. 3, p. 433-440, 2012a. 10.1590/S0100-67622012000300005.

PACHECO, M. V.; MATOS, V. P. Método para superação de dormência tegumentar em sementes de Apeiba tibourbou Aubl. Revista Brasileira de Ciências Agrárias, Recife, v. 4, n. 1, p. 62 66, 2009. 10.5039/agraria.v4i1a10.

PINHEIRO, R. M.; SANTOS, E. A.; MORAES, K. N. O.; FERREIRA, E. J. L. Emergência de plântulas e caracterização morfométrica de frutos e sementes de Bacabinha (Oenocarpus mapora h. karsten. arecaceae). Revista da Jornada de PósGraduação e Pesquisa-Congrega Urcamp, v. 14. n. 14, 2017.

PORTO, B. S. M.; SILVA, W. J.; AQUINO, J. D.; SOUSA, N. S.; SILVA, M. E. F.; PEREIRA, G. F.; GIANNINI, M. A.; SILVA, L. M.; SOUZA, T. L.; VIEIRA, T. C.; MORAIS, C. R. Avaliação de diferentes métodos artificiais na superação de quebra de dormência em Ormosia arbórea. Revista GETEC, v. 8 , n. 21, p. 41-57, 2019.

RODRIGUES, A. C. C. et al. Biometria de frutos e sementes e grau de umidade de sementes de angico (Anadenanthera colubrina (vell.) brenan var. cebil (griseb.) altschul) procedentes de duas áreas distintas. Revista Científica Eletrônica de Engenharia Florestal, v. 4, n. 8, p. 1-15, ago. 2006.

ROSA, F. C. D.; REINIGER, L. R. S.; SILVEIRA, L. R.; GOLLE, D. P.; MUNIZ, M. F. B.; CURTI, A. R. Superação da dormência e germinação in vitro de sementes de bracatinga (Mimosa scabrella Bentham). Semina: Ciências Agrárias, v. 33, n. 3, p. 1021-1026, 2012. 10.5433/1679-0359.2012v33n3p1021.

SANTOS, G. R.; SANTOS, E. M. C.; LIRA, E. S.; GOMES, D. L.; SOUZA, M. A.; ARAÚJO, K. D. Análise da precipitação pluvial e temperatura média do ar de Olho D’Água do Casado, Delmiro Gouveia e Piranhas, Alagoas. Revista de Geociências do Nordeste, Caicó, v. 3, n. 1, p. 16-27, 2017.

SANTOS, J. C. C.; LIMA, A. N. S.; SILVA, D. M. R.; COSTA, R. N.; AMORIM, D. J.; SILVA, J. V.; SANTOS NETO, A. L. Análise biométrica multidimensional com tratamentos prégerminativos em sementes e caracterização morfológica de plântulas de Mimosa bimucronata (De Candolle) Otto Kuntze. Revista de Ciências Agrárias, v. 42, n. 2, p. 418-429, 2019. 10.19084/rca.17169.

SARMENTO, H. G. S; DAVID, A. M. S.; BARBOSA, M. G; NOBRE, D. A. C; AMARO, H. T. R. Determinação do teor de água em sementes de milho, feijão e pinhão-manso por métodos alternativos. Energia Agricola, Botucatu, v. 30, n. 3, p. 249-256, 2015. 10.17224/EnergAgric.2015v30n3p250-256.

SILVA, M. S.; BORGES, E. E. L.; LEITE, H. G.; CORTE, V. B. Biometria de frutos e sementes de Melanoxylon brauna Schott. (Fabaceae-Caesalpinioideae). Cerne, v. 19, n. 3, p. 517524, 2013. 10.1590/S0104-77602013000300020. 
SILVA, R. M.; CARDOSO, A. D.; DUTRA, F. V.; MORAIS, O. M. Aspectos biométricos de frutos e sementes de Caesalpinia ferrea Mart. ex Tul. provenientes do semiárido baiano. Revista de Agricultura Neotropical, v. 4, n. 3, p. 85-91, jul/set., 2017. 10.32404/REAN.V4I3.1427.

VALADARES, J.; PAULA, R. C.; MORO, V. V. Germinação, desenvolvimento de plântulas e teste de tetrazólio em Poecilanthe parviflora Bentham (Fabaceae - Faboideae). Científica, Jaboticabal, v. 37, n. 1, p. 39-47, 2009. $\underline{10.15361 / 1984-5529.2009 v 37 n 1 p 39+-+47}$

VASCONCELOS, A. D. M.; HENRIQUES, I. G. N.; SOUZA, M. P.; SANTOS, W. S.; SANTOS, W. S.; RAMOS, G. G. Caracterização florística e fitossociológica em área de Caatinga para fins de manejo florestal no município de São Francisco-PI. Agropecuária Científica no Semiárido, Patos, v. 13, n. 4, p. 329337, 2017. 10.30969/acsa.v13i4.967. 